\title{
BMJ Open Informed consent, shared-decision making and a reasonable patient's wishes based on a cross-sectional, national survey in the USA using a hypothetical scenario
}

\author{
John T James, ${ }^{1}$ Darwin Jay Eakins, ${ }^{2}$ Robert R Scully ${ }^{3}$
}

To cite: James JT, Eakins DJ, Scully RR. Informed consent, shared-decision making and a reasonable patient's wishes based on a crosssectional, national survey in the USA using a hypothetical scenario. BMJ Open 2019;9:e028957. doi:10.1136/ bmjopen-2019-028957

- Prepublication history and additional material for this paper are available online. To view these files, please visit the journal online (http://dx.doi org/10.1136/bmjopen-2019028957).

Received 07 January 2019 Revised 12 July 2019 Accepted 12 July 2019

\section{Check for updates}

(c) Author(s) (or their employer(s)) 2019. Re-use permitted under CC BY-NC. No commercial re-use. See rights and permissions. Published by BMJ.

${ }^{1}$ CEO, Patient Safety America, Houston, Texas, USA

${ }^{2}$ University of Kansas, Lawrence, Kansas, USA

${ }^{3}$ Private Collaborator, Houston, Texas, USA

Correspondence to

Dr John T James;

john.t.james@earthlink.net

\section{ABSTRACT}

Objective In approximately half the states in the USA, and more recently in the UK, informed consent is legally defined as what a reasonable patient would wish to know. Our objective was to discern the information needs of a hospitalised, 'reasonable patient' during the informedconsent process.

Design We performed a cross-sectional study to develop a survey instrument and better define 'reasonable person' in relation to informed consent in a hypothetical scenario where an invasive procedure may be an option.

Setting A 10-question survey was administered from April 19 through 22 0ctober 2018 to three groups: student nurses $(n=76)$, health professions educators $(n=63)$ and a US national population $(\mathrm{n}=1067)$.

Primary and secondary outcome measures The primary outcome measure was the average intensity, on a 5-point scale, by which survey groups wished to have each of 10 questions answered. The secondary outcome was to discern relationships between survey demographics and the intensity by which participants wanted an answer.

Results Despite substantial demographic differences in the nursing-student group and health-professionseducator group, the average intensity scores were within 0.2 units on nine of 10 questions. The national survey revealed a strong desire to have an answer to each question (range 3.98-4.60 units). It showed that women desired answers more than men and older adults desired answers more than younger adults.

Conclusions Based on responses to 10 survey questions regarding wishes of people in a situation where an invasive procedure may be necessary, the vast majority want an answer to each question. They wanted to know about all treatment options, risky drugs, decision aids, who will perform the procedure, and the cost. They wanted their advocate present, periodic review of their medical record, a full day to review documents and expected outcomes and restrictions after the procedure.

\section{INTRODUCTION}

The human right to self-determination in healthcare is a hallmark of instruments promulgated by the United Nations. Rights
Strengths and limitations of this study

- Based on two targeted surveys and a national survey, findings are consistent across demographic groups and across the USA, making our conclusions robust.

- The findings form a template that could be used by clinicians when engaged in shared-decision making to elicit truly informed consent from the patient.

- The survey questions had to be limited to be practical, so in any specific, real-life situation additional questions may be asked by a reasonable patient.

- Findings about the out-of-pocket costs of a procedure probably apply only to patients in the USA where out-of-pocket costs may be enormous.

- Our survey was limited by requirements to read English and have electronic access.

are specifically described for children, persons with disabilities and older persons. These call for the highest standards attainable for children's health, ${ }^{1}$ for treatment of illness or rehabilitation of the disabled, ${ }^{2}$ and for maintenance of optimum health as people age. ${ }^{3}$ The patient's right to know certainly extends to knowing the risks and benefits of prescription medications. For example, based on a recent court decision in the UK involving off label and unlicensed medication prescribing, consent laws now call for patients to receive all information that a patient deems important, and not just what the physician thinks is important. ${ }^{4}$ However, unless the patient is harmed by denial of sufficient information to exercise their rights to make an informed decision about off-label prescriptions, there is no legal standing for compensation. In our opinion, the human rights of patients to self-determination in healthcare can only be attained through a 
balanced process of shared-decision making between patient and clinician.

While the idea of shared-decision making between patient and clinician has been around many decades, based on peer-reviewed citations, the concept has gained momentum since 2012. ${ }^{5}$ The culmination of shared-decision making is that the patient consents to the mutually agreed procedures to be performed or not performed. The old standard calling for information that 'reasonable clinicians' feel their patients need to know is giving way to the new standard defined by what a reasonable patient wishes to know. However, a study of recorded conversations between clinicians and a patients that may need percutaneous coronary intervention (PCI) found that only $3 \%$ of the patients received all eight elements necessary for informed decision making. ${ }^{6}$ A recent court ruling in the UK has upheld the patient-centred, informed-consent standard and about half of the USA states use 'reasonable patient' as the basis for administering informed consent. ${ }^{7}$ In the past, the 'reasonable patient' standard has been ill-defined and abstract; our intent is to better-define the information wishes of a reasonable person when facing the possibility of an invasive procedure. ${ }^{8}$ There is a natural conflict between respect for patient autonomy in making an informed decision and the practical aspects of how a clinician delivers information to a 'reasonable patient' to fulfil the ethical principle of autonomy.

The question then becomes, 'What does a reasonable patient wish to know?' Typically, that is answered after the fact in specific cases where a patient may allege that he was not given sufficient information to make an informed decision. ${ }^{9}$ One example involved a case where a man's family was not given enough information about his defibrillator replacement to make an informed decision. ${ }^{10}$ Patient preferences were not elicited by the clinician. A court in the UK decided that a woman was not given sufficient information on the $1 \%$ risk of shoulder dystocia from a vaginal versus a Caesarian delivery to make an informed decision. ${ }^{11}$ To our knowledge, no investigators have attempted to define the information needs of a reasonable patient in a general way that applies to care during hospitalisation. To some extent the survey was driven by stories of patient advocates who have experienced harm and, in retrospect, wish they had known more about the risks of their treatment, device, or medication. We hypothesised that such wishes could be generalised into information a 'reasonable patient' would want to know.

\section{GOAL}

Our primary goal was to establish the descriptive intensity (scale of $1-5$, with 1 being 'definitely no' and 5 being 'definitely yes') by which answers to general questions are desired by a reasonable patient before giving consent for an invasive procedure, prescription drugs, or medical devices that could pose a risk of avoidable harm. Our secondary goal was to characterise heterogeneity, such as gender and age, in the survey groups that may be associated with intensity variations in what a reasonable patient wishes to know.

\section{METHODS}

Our survey-study proposal (online supplementary file 1) was approved by the Galveston College Institutional Review Board. Our search of peer-reviewed literature using 'reasonable patient survey' (15 November 2018) discovered only two partially relevant articles. One involved wishes of patients about anaesthesia risks in a Singapore hospital. ${ }^{12}$ Another surveyed patients' opinions about presurgical informed-consent in a Jamaica teaching hospital. ${ }^{13}$ In the latter study, $67 \%$ of the surveyed patients described their consent process as 'unsatisfactory'. We created a statement of a generic situation in which a hospitalised patient must make choices about their care after being stabilised on entry via the emergency department: You are hospitalised in a large, urban, teaching hospital after being brought into its emergency room last night. The condition that brought you to the ER has been stabilised, but additional procedures may be necessary. The following 10 questions determine what you would like to know as a reasonable patient. We developed a 10-question survey based on adverse experiences reported by members of the Patient Safety Action Network (formerly members of the Safe Patient Project of Consumers Union) and our knowledge of shortcomings with current informed consent practices as reflected in medical literature.

The survey was developed in two forms. The first employed demographics to include age, gender, education level, race or ethnicity, and whether the survey taker has worked in a hospital (online supplementary file 2). This survey was administered via cell phone, without any means of coercion, to student nurses (and a few faculty) on 19 April 2018 at Galveston College, Galveston Texas during a presentation by Dr James. All present in the lecture hall were verbally recruited to take the survey at the start of the presentation, and then the survey results were shared at the conclusion of the talk. It was also administered to participants in the Health Professions Educators Summer Symposium (HPESS) Community via email request on 8 June 2018. The master-list of past participants in summer symposia was used as the recruitment tool. The latter included primarily mature academics involved in educating physicians, nurses and healthcare administrators.

The second form of the survey, which was used for the US national survey, employed an identical scenario and questions, but the demographics were adapted to those offered by SurveyMonkey (SM) for a national survey (online supplementary file 3). These included age, gender, household income level and region of the USA. The national platform included survey takers across the USA that had been previously recruited by SM as part of their nationally representative database. The vast majority of the national survey takers used cell phones to answer 
the questions. The third survey was administered to the national audience on 22 October 2018.

Each of the 10 questions could be answered at one of five intensity levels indicating the degree to which an answer is desired by the person taking the survey. The responses were as follows: definitely no (1.0), probably no (2.0), neutral (3.0), probably yes (4.0) and definitely yes (5.0). Formal statistical analyses were adapted to the qualitative nature of our study design. Final conclusions are word descriptions of the intensity of desire of a reasonable patient to have answers such as 'probably yes' or 'definitely yes'. Obvious trends in the data were captured graphically.

\section{Statistics and factor analyses}

The data subjected to analyses were collected in three surveys (student nurses, HPESS and the national survey). For each survey, descriptive statistics were obtained and analyses of the results were performed using Stata (V.14.0). The means of the responses of the various groups for each subject category (eg, age, gender, etc) were tested for differences using methods that are appropriate for these categorical variables, which are not normally distributed. The non-parametric Kruskal-Wallis one-way analysis of variance by ranks was performed to test for differences between means and the Dunn test was used to identify pairs that differed significantly. Statistical significance, adjusted for false discovery, was established with $\mathrm{p}<0.025$.

Factor analysis with principal component factoring was utilised in all surveys to determine components that can explain the greatest portions of the total variance in responses among the questions. The goal of a factor analysis is to reduce the number of variables to explain and to interpret the results. Factor loadings were achieved by regression of scoring coefficients obtained with varimax rotation. The loaded factors (principal components) generated were analysed as described above for other variables.

\section{Patient and public involvement}

The development of our research plan was a direct result of patient advocates' experiences with failed informed consent. These experiences led to formulation of many of the questions posed in our survey. Our results will be disseminated to the HPESS community once the study has been published. Results will be disseminated to student nurses at Galveston College through a presentation this spring. Our findings and suggested actions from our findings will be disseminated to patient advocates whose shared ideas and experiences powered this study. Those groups include the following: Patient Council of the Right Care Alliance, Patient Safety Action Network and members of Patient Safety America. We expect to widely share our findings with the general public (represented by our national survey) through media outlets such as ProPublica, with physicians through KevinMD and Veritas Health Care, and with nurses through Quality and Safety Education for Nurses.

\section{RESULTS}

We targeted two groups from which to obtain responses because of the access we had to them and the expectation that their demographics would be different. The response rate from the student nurses was 99\% (76/77) because it was taken during a lecture in which support was available if anyone had difficulty. Only one did. The response rate of the HPESS Community to the email request was $63 / 146=43 \%$. The low response is likely due to busy professionals not having time to read and respond to all emails sent to them. Combined, the response rate of the two targeted studies was $62 \%$. Table 1 shows the diversity of demographics in the two groups that took initial surveys. The primary differences were in age, education level, race or ethnic origin, and hospital work experience (online supplementary file 4 ).

Table 1 Comparative demographics of targeted groups (two sample test of proportions)

\begin{tabular}{lccc}
\hline Demographic measure & Student nurses $(\mathbf{n = 7 6 )} \mathbf{( \% )}$ & $\begin{array}{l}\text { HPESS community }(\mathbf{n}=63) \\
\mathbf{( \% )}\end{array}$ & P value \\
\hline Under 35 years of age & 77 & 3 & $<0.0001$ \\
Female & 78 & 2 & 0.2755 \\
High school graduate & 34 & 5 & $<0.0001$ \\
College graduate & 65 & 93 & $<0.0001$ \\
Advanced degree & 1 & 84 & $<0.0001$ \\
White or Caucasian & 51 & 3 & $<0.0001$ \\
Black or African American & 16 & 2 & 0.0151 \\
Hispanic or Latino & 26 & 6 & 0.0001 \\
Asian & 4 & 86 & 0.5161 \\
Have worked in a hospital & 35 & & $<0.0001$
\end{tabular}

HPESS, Health Professions Educators Summer Symposium. 
The national survey included 1211 persons who entered the survey and 1067 who completed it for a response rate of $88 \%$. Nine participants did not answer location questions.

The combined results of our three surveys consistently showed that a 'reasonable patient' would want to know an answer to each of the 10 questions presented in our survey (table 2).

Table 2 allows the reader to view the results in two ways for each of the 10 questions. The first, shown in bold parentheses, is the fraction of responders that indicated that they definitely wanted to know information (5.0 response) or have a certain right to access (eg, medical record access). The second way to view results, in black lettering, indicates the numerical mean of all responses in each of the three surveys and the ranges of the means sorted by income groups and regions of the USA in the national survey. We used ranges as a measure of dispersion around the national means because it is likely lay readers will understand this more readily than the results of our formal statistical analysis. The three distinct surveys compare well regarding the wishes of patients. The highest intensity of desire to have an answer was to question 1 (know all treatment choices) in all three surveys (range 4.58-4.94). In all three surveys, the lowest intensity of desire to have an answer was to question 8 (medical record access) (range 3.98-4.07), and the second lowest intensity was to question 9 (advanced review of documents) (range 4.18-4.29). Even the lowest intensity desire for an answer was near 4.0, which implies that on weighted-average basis, the putative reasonable patient would probably want to have access to his medical record and be able to make entries.

Below we provide brief descriptions of the statistical analyses and factor analyses for each of the three surveys. The details of these analyses are in supplementary files. Question numbers are found in table 2. Statistical analysis of the responses to survey questions obtained from student nurses (online supplementary file 5) revealed no significant differences among age groups, level of education, experience working in a hospital, or between genders, in their responses to any of the 10 questions. Not considering 'another race' as a response suitable for comparisons, the only differences in pairs were for question 1. 'White or Caucasian' was different from 'Black or African American' ( $\mathrm{p}=0.011)$ and 'Black or African American' was different from 'Asian or Asian American' $(\mathrm{p}=0.020)$.

Factor analysis with principal component factoring identified three factors each with Eigenvalues greater than 1 , which cumulatively accounted for $64 \%$ of total variance among responses provided by the student nurses. Varimax factor loading of three factor variables labelled as 'knowledge', 'participation' and 'total cost' were generated and analysed as above for differences in responses among groups (online supplementary file 6 ). No significant differences were found among age groups, levels of education, or between genders, in their responses to any of the factor variables. The only significant differences, again disregarding comparisons to 'Another race', existed among races and ethnicities in their responses associated with 'knowledge' ( $\mathrm{p}=0.0091)$ where 'White or Caucasian' differed from 'Black or African American' ( $\mathrm{p}=0.0211$ ).

The responses of the HPESS survey did not differ significantly between genders, or among various ethnicities for any of the ten questions (online supplementary file 7$)$. Responses differed significantly among age groups only for questions $1(\mathrm{p}=0.0171)$ and $2(\mathrm{p}=0.0024)$. Responses differed significantly by education level for questions $1 \quad(p=0.0015), 2 \quad(p=0.0139), 3 \quad(p=0.0170)$ and $10(\mathrm{p}=0.0347)$. Among respondents to the HPESS survey, significant differences in responses to questions 1 $(\mathrm{p}=0.003), 2(\mathrm{p}=0.0024)$ and $5(\mathrm{p}=0.0002)$ were provided by respondents who differed according to their employment as hospital workers.

Factor analysis of the HPESS data with principal component factoring identified no statistically significant differences for either of two factor variables 'knowledge' and 'participation' when responses were compared by age, gender, or level of education (online supplementary file 8). A significant difference among ethnic groups was found for 'knowledge' ( $p=0.0394)$ but post hoc analysis with Dunn's test failed to identify any pairs of groups that differed significantly.

In the national survey, responses differed significantly for all questions among age groups $(p=0.001$ for questions $1-7$ and $10 ; \mathrm{p}=0.0041$ and 0.0052 for questions 8 and 9 , respectively), between genders $(\mathrm{p}=0.001$ for questions $1,2,4,7,8$ and $10 ; \mathrm{p}=0.0043,0.0002,0.0030$ and 0.0014 for questions 3, 5, 6 and 9, respectively) (online supplementary file 9). Significant differences for questions 1 $(\mathrm{p}=0.0001), 2 \quad(\mathrm{p}=0.0384), 3 \quad(\mathrm{p}=0.0047), 4 \quad(\mathrm{p}=0.0037)$ and $6 \quad(\mathrm{p}=0.0190)$ were found among groups that differed by income level. Question $9(\mathrm{p}=0.0473)$ was the only question for which responses differed significantly among regions of the USA. Several salient generalisations from these comparisons are apparent. When comparing responses among various age groups, differences were found among all ages groups for most questions. When significant differences were found among responses of groups of differing income levels the differences, most often, were between group 1 and the other groups. Differences between regions, in response to question 9, were most often between regions 1 and 2 and the other regions.

Factor analysis of the national data with principal component factoring demonstrated significant differences among the age categories for both factor variables ('knowledge' and 'other', $\mathrm{p}=0.0001$ for both variables) (online supplementary file 10). All groups differed significantly from each other, with the exception of group 4 versus group 5 for the factor variable 'other'. For both factor variables the differences in responses of the genders are very highly significantly different $(\mathrm{p}<0.0001)$. When considering responses from groups of differing income levels, significant differences were found for the variable 'knowledge' $(\mathrm{p}=0.0005)$. Most of the differences among pairs are between group 1 and other groups and between group 3 and other groups. 


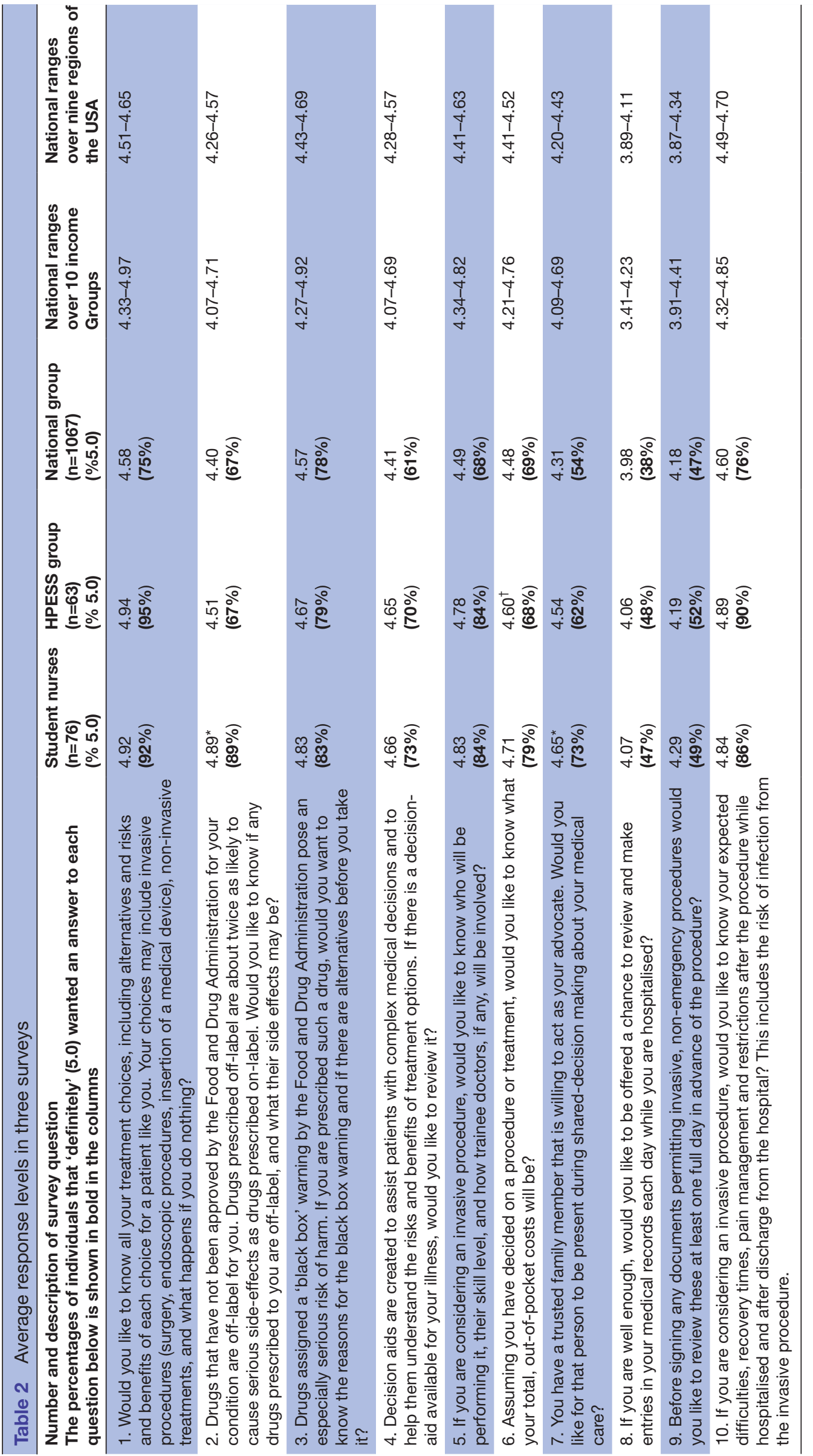

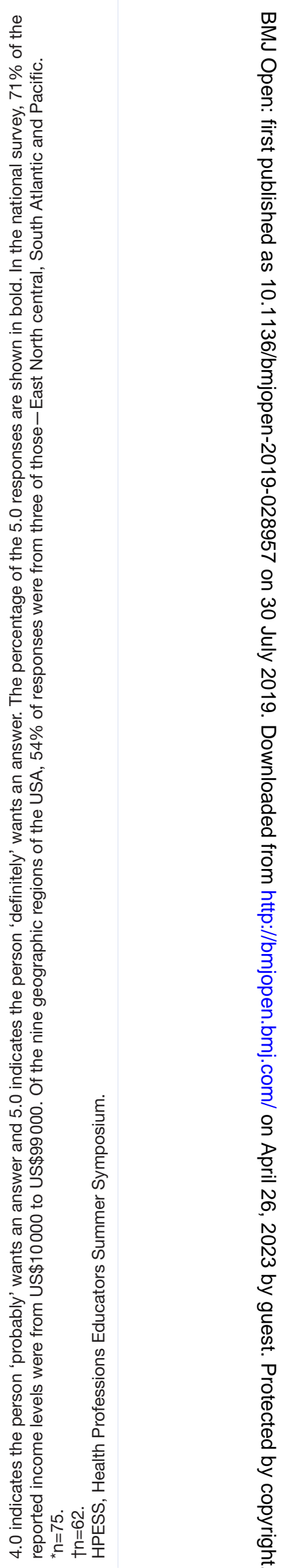




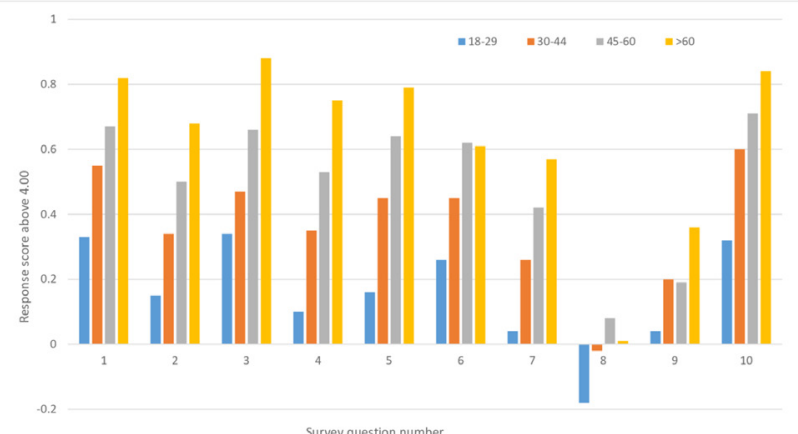

Figure 2 National intensity scores above 4.0 versus question number for age differences in the national survey. Responses came from 297, 230, 343 and 197 people in the four respective age groups.

There were no significant differences in responses to factor variables among regions.

\section{DISCUSSION}

Despite the different demographics in the two targeted surveys (table 1), especially in age, education level and hospital work experience, the responses were comparable in the two groups (table 2). Only one of the 10 questions (number 2) had a response level that differed by more than 0.20 units. This was the question of whether a reasonable patient would want to know about any off-label drugs prescribed. The difference was 0.38 units. The higher education level and more hospital experience of the HPESS Community may have made this group slightly less concerned about the additional risk that may be associated with off-label prescriptions. Statistical analysis of the nurse-student survey revealed two paired demographic differences. Two race/ethnic pairs (white vs black and black vs Asian) were associated with differences in intensity of response to question 1, which is about knowing all choices for treatment including risks and benefits. Statistical analysis of the HPESS community survey disclosed differences between pairs in the age,

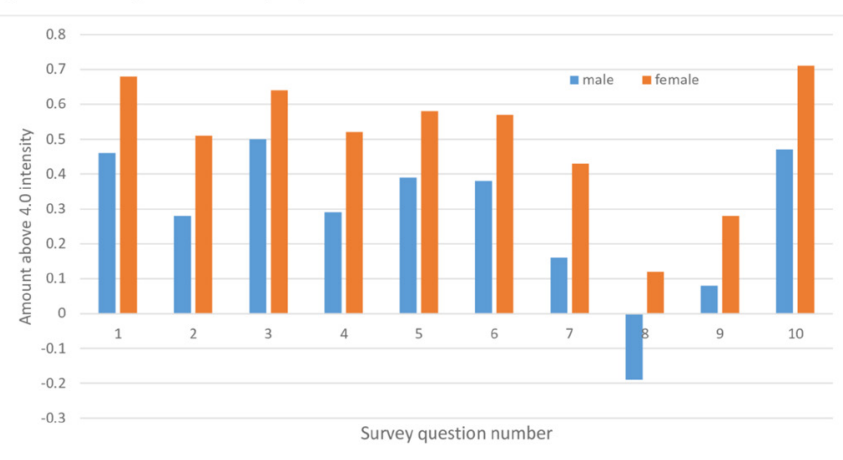

Figure 1 National intensity scores above 4.0 versus question number for gender differences in the national survey. Responses came from 497 males and 570 females. education-level and hospital-work-experience groups. While these statistical findings may be interesting, the reality is that the core message remains unchanged: patients of all types studied wish to know many details about their care choices when facing the possibility of an invasive procedure.

The results of the national survey regarding demographics of gender (figure 1) and age (figure 2) demonstrated distinct trends for all 10 questions. Without exception, women wanted more information than men, and older adults wanted more information than younger adults. Similarly, statistical analysis supported associations between age and gender on the intensity of responses to most questions, and it revealed an effect of income for some of the survey questions. The gender associations may be due to women being higher users of hospital care and hospitals tending to offer many more services targeted to women than to men. ${ }^{14}$ Older adults may be more likely to be cautious compared with younger adults because of more lifetime hospital experiences.

Our survey provides insight into some patient concerns that are not typically part of informed consent. In the wake of the opioid epidemic, the public is more aware of the potential dangers of prescription drugs. Thus, it should not be surprising that patients would want to know if the drugs prescribed to them are off-label or have a black-box warning. The US Food and Drug Administration assigned 'black box' warnings to immediate-release opioids in $2016 .{ }^{15}$ There is also growing attention to surprise medical bills in the USA, so a reasonable patient would likely to want an estimate of his out-of-pocket costs. Inordinate out-of-pocket costs, especially those that lead to bankruptcy, may have an adverse effect on clinical outcomes. ${ }^{16}$ Hospital administration staff could assist with providing cost information. The opportunity to review and make entries in one's medical record, while not part of the informed consent process, may relate. Many patients want to ensure that the data being recorded are accurate and complete; moreover, many desire access to their data as a means of gaining a better understanding of their condition and engaging with their providers. Encouraging this access can convey strong support for the view that the patient is an integral part of his care team.

There is an important connexion between informed consent and the overuse of medical procedures. The overuse of PCI in the USA is a prime example. Patients that may need PCI were less likely to choose this invasive option when they were better informed about their care options during hospitalisation. ${ }^{17}$ A study of patients in Northern England that may need PCI concluded that there is 'a mismatch between legal and ethical principles of informed consent and current practice. The variation in patients' experiences of the current place of informed consent in service delivery represents a missed opportunity for cardiologists to work in decision-making partnerships with patients. In light of recent changes in the law [to the reasonable patient standard], a new approach to informed consent is required'. ${ }^{18}$ 
The history of legally defined informed consent for invasive procedures has evolved from a totally physician-centred concept (before the Era of Enlightenment) in which deception of the patient was deemed necessary, to the point where the process has now become patient-centred, in principle. A brief summary of some of the court decisions pertinent to involvement of the patient points to the next step in informed consent, which we feel we have defined with our survey. ${ }^{19}$ As early as 1914, a New York court established that an 'adult in sound mind has the right to determine what shall be done with his own body'. This was reinforced in 1960 by the decision of a court in Kansas that the patient, not the physician, must make the final decision about any operation. Of course, the patient's decision may be biassed by receiving limited information from the physician. Two court decisions in 1972, one in California and the other in Washington, DC, determined that the patient must be informed of pertinent risks of surgery and have the alternatives revealed to him or her. In 1983, a New Jersey court ruled that if a surgeon, other than the one the patient selected, performs the surgery, then the surgeon that obtained consent, but did not perform the surgery is liable for malpractice. The surgeon performing the surgery is liable for battery. The importance of the side effects of a drug (prednisone) came to a Massachusetts court's attention in 1986 when a patient suffered serious adverse effects of this drug used after eye surgery. It seems there was controversy about whether the physician should have known about the possible side effects, and then disclosed this potential complication of the drug to the patient.

While our survey questions originated primarily from adverse experiences of patients, it is clear that court decisions have pointed the way to a new era of the patient's voice being heard in the context of shared-decision making and informed consent. That voice says to clinicians who would perform an invasive procedure, "We patients want to know more than you have been telling us". We want to know all of our choices and their risks and benefits, we want to know the risks and benefits of drugs prescribed to us and devices placed in us, we want to view decision aids when available, we want to know the skill level of the physician(s) performing our procedure, and we want to know our costs. Moreover, we want an advocate present during shared-decision making, we want full access to our medical records, we want to review consent documents at least 24 hours before signing them, and we want to know the expected outcomes of the invasive procedure to include recovery times, pain management and infection risks.

\section{LIMITATIONS}

In order to respect the time of responders to our survey, we limited it to 10 questions applicable to an informed consent discussion in a hypothetical situation. In real clinical settings, it is likely that our 'template' will need to be augmented with questions specific to the situation the patient faces. These should be designed to elicit the patient's preferences. We also recognise that some of the answers are out of the clinician's hands; for example, clinicians in the USA are seldom going to know the patient's out-of-pocket costs. We also recognise that clinicians may need the assistance of pharmacists in conveying the benefits, risks, and alternatives to off-label or black-box-warning drugs. Surveys like ours involving a hypothetical scenario may be limited because in a real and stressful situation a patient may simply want to trust doctors' recommendations or may be afraid to ask too many questions. In a sense, our hypothetical 'reasonable patient' has become a 'frightened patient' when placed in a real situation, but that does not mean that he or she does not want to know answers to the all the questions in our survey.

Selection bias is always a possibility in surveys such as ours. Survey takers were recruited from the three different groups to which we had access. One clear bias is that the survey platform was electronic and written in English, eliminating any potential responses from people that do not have electronic access or do not read English well enough to participate in the survey. The number of adult Americans who cannot read has been estimated at about 32 million. ${ }^{20}$ Our results do not apply to populations outside the USA where there may be higher or lower trust of the healthcare delivery system, or where people are desperate to get any medical care. Despite large demographic differences in the smaller survey populations (table 1) and the different methods of recruitment in all three surveys, the consistency of the results across the three surveys suggests that the data in table 2 are representative of the majority of people living in the USA.

\section{CONCLUSIONS}

Through two targeted surveys and a US national survey, we have affirmed that a reasonable patient will want to know far more information than is generally conveyed during typical shared-decision making that leads to no more than a partly informed decision by the patient. Survey respondents wanted to know risks and benefits of all treatment options, the risks and benefits of off-label and box-warning drugs. They wished to view decision aids, know precisely who will perform the procedure, and their anticipated out-of-pocket costs. Their desire was for an advocate to be present during shared-decision making, have periodic opportunities to review their medical record, have a full day to review informed-consent documents, and to be made aware of expected outcomes and restrictions after the procedure. We expect our findings to have implications for what defines a reasonable patient standard for informed consent.

Contributors JTJ conceived the study and developed the questions. DJE formed the survey instrument to suit each of the situations where questions were to be presented to a survey audience. JTJ and RRS analysed the data. JTJ wrote most of the paper in close consultation with coauthors. All authors agreed to be accountable for accuracy of the work. 
Funding The study was supported by Patient Safety America, Houston, Texas, USA. A donation (US\$1400) from Dr James to support the SurveyMonkey platform provided the funds required. His roles are given below in the Author's contribution section.

Competing interests Dr James founded Patient Safety America as a no-budget organisation dedicated to educating people about problems in the US healthcare industry. He serves as its unpaid CEO and leader. He has no conflicts of interest, advocating only for improved care.

Patient consent for publication Not required.

Provenance and peer review Not commissioned; externally peer reviewed.

Data availability statement Data are available in a public, open access repository. National survey data at: http://patientsafetyamerica.com/survey-data/ Health-Professions-Educator survey at: https://www.surveymonkey.com/results/ SM-DQJDBBQ7L/ Nursing-student survey available at: https://www.surveymonkey. com/results/SM-5F2SX9W3V/ Available 'Supplementary files' include the research proposal, 2 forms of the survey, and 6 statistical analysis files.

Open access This is an open access article distributed in accordance with the Creative Commons Attribution Non Commercial (CC BY-NC 4.0) license, which permits others to distribute, remix, adapt, build upon this work non-commercially, and license their derivative works on different terms, provided the original work is properly cited, appropriate credit is given, any changes made indicated, and the use is non-commercial. See: http://creativecommons.org/licenses/by-nc/4.0/.

\section{REFERENCES}

1. United Nations Human Rights. Convention on the rights of the child. Available: https://www.ohchr.org/EN/Professionallnterest/Pages/ CRC.aspx [Accessed 10 Apr 2019].

2. United Nations Human Rights. Committee on the rights of persons with disabilities. Available: https://www.ohchr.org/EN/HRBodies/ CRPD/Pages/ConventionRightsPersonsWithDisabilities.aspx\#25 [Accessed 10 Apr 2019].

3. United Nations Human Rights. United nations principles for older persons. Available: https://www.ohchr.org/EN/Professionallnterest/ Pages/OlderPersons.aspx [Accessed 10 Apr 2019].

4. Aagaard L, Kristensen K. Off-label and unlicensed prescribing in Europe: implications for patients' informed consent and liability. Int $J$ Clin Pharm 2018;40:509-12.
5. Accad M. The case against shared-decision making. Part 1. The history of a nebulous idea. The progress notes of Michel Accad, MD. Available: http://alertandoriented.com/the-case-against-shareddecision-making-1/ [Accessed 12 Nov 2018].

6. Rothberg MB, Sivalingam SK, Kleppel R, et al. Informed decision making for percutaneous coronary intervention for stable coronary disease. JAMA Intern Med 2015;175:1199.

7. Spatz ES, Krumholz HM, Moulton BW. The new era of informed consent: getting to a Reasonable-Patient standard through shared decision making. JAMA 2016;315:2063-4.

8. Beauchamp TL, Childress JF. Principles of biomedical ethics. 123. 6th edn. Oxford University Press, 2009.

9. Murray B. Informed consent: what a must a physician disclose to a patient? AMA J Ethics 2012;14:563-6.

10. Diaconis P. I wish someone had told us the risks and benefits of replacing my father's defibrillator. JAMA Intern Med 2016;176:885.

11. Spatz ES, Krumholz HM, Moulton BW. Informed consent and the Reasonable-Patient Standard-Reply. JAMA 2016;316:993-4.

12. Yek JLJ, Lee AKY, Tan JAD, et al. Defining reasonable patient standard and preference for shared decision making among patients undergoing anaesthesia in Singapore. BMC Med Ethics 2017;18:6.

13. Cawich SO, Barnett AT, Crandon IW, et al. From the patient's perspective: is there a need to improve the quality of informed consent for surgery in training hospitals? Perm J 2013;17:22-6.

14. Choy J, Kashanian JA, Sharma V, et al. The men's health center: Disparities in gender specific health services among the top 50 "best hospitals" in America. Asian J Urol 2015;2:170-4.

15. Fda Boxed warning for immediate-release opioids. J Pain Palliat Care Pharmacother 2016;30:141-5.

16. Ramsey SD, Bansal A, Fedorenko CR, et al. Financial Insolvency as a risk factor for early mortality among patients with cancer. J Clin Oncol 2016;34:980-6.

17. Rothberg MB, Sivalingam SK, Kleppel R, et al. Informed decision making for percutaneous coronary intervention for stable coronary disease. JAMA Intern Med 2015;175:1199-206.

18. Probyn J, Greenhalgh J, Holt J, et al. Percutaneous coronary intervention patients' and cardiologists' experiences of the informed consent process in northern England: a qualitative study. BMJ Open 2017;7:e015127.

19. Murray PM. The history of informed consent. lowa Orthop $J$ 1990;10:104-9.

20. One Young World. 32 million American adults can't read: why literacy is the key to growth, 2018. Available: https://medium.com/@ OneYoungWorld_/32-million-american-adults-cant-read-why-literacyis-the-key-to-growth-818996739523 